5 Paisey RB, Macfarlane DG, Sherriff RJ, Hartog M, Slade RR, White DAJ. The relationship between blood glycosylated haemoglobin and home capillary blood glucose levels in diabetics. Diabetologia 1980;19: 31-4.

${ }^{6}$ Dunn PJ, Cole RA, Soeldner JS, et al. Temporal relationship of glycosylated haemoglobin concentrations to glucose control in diabetics. Diabetologia 1979;17:213-20.

${ }^{7}$ Bunn HF, Haney DN, Kamin S, Gabbay KH, Gallop PM. The biosynthesis of human hemoglobin $\mathrm{A}_{1} \mathrm{c}$. Slow glycosylation of hemoglobin in vivo. $\mathcal{F}$ Clin Invest $1976 ; 57: 1652-9$.

8 Saddi R, Wajcman H, Eschwege E, Levy R, Duchateau A. Glycosylated haemoglobin in patients on venesection therapy for haemochromatosis. Lancet 1980;ii:141-2.

${ }^{9}$ Brooks AP, Metcalfe J, Day JL, Edwards MS. Iron deficiency and glycosylated haemoglobin $\mathrm{A}_{1}$. Lancet $1980 ; \mathrm{ii}: 141$.

${ }^{10}$ De Boer M-J, Miedema K, Casparie AF. Glycosylated haemoglobin in renal failure. Diabetologia $1980 ; 18: 437-40$.

11 Dandona P, Freedman D, Moorhead JF. Glycosylated haemoglobin in chronic renal failure. $\mathrm{Br}$ Med $\mathcal{F} 1979 ; \mathrm{i}: 1183-4$.

12 Svendsen PA, Christiansen JS, Segaard U, Welinder BS, Nerup J. Rapid changes in chromatographically determined haemoglobin $A_{1}$ induced by short-term changes in glucose concentration. Diabetologia 1980;19: 130-6.

13 Bolli G, Cartechini MG, Compagnucci P, et al. Modification of glycosylated haemoglobin concentration during artificial endocrine pancreas treatment of diabetics. Diabetologia 1980;18:125-30.

14 Boden G, Master RW, Gordon SS, Shuman CR, Owen OE. Monitoring metabolic control in diabetic outpatients with glycosylated hemoglobin. Ann Intern Med 1980;92:357-60.

15 Brooks AP, Nairn IM, Baird JD. Changes in glycosylated haemoglobin after poor control in insulin-dependent diabetics. $\mathrm{Br} \mathrm{Med} \mathcal{f} 1980$; $281: 707-10$.

16 Goldstein DE, Peth SB, England JD, Hess RL, Da Costa J. Effects of acute changes in blood glucose on $\mathrm{HbA}_{1}$. Diabetes $1980 ; 29: 623-8$.

17 Gabbay KH, Hasty K, Breslow JL, Ellison RC, Bunn HF, Gallop PM. Glycosylated hemoglobins and long-term blood glucose control in diabetes mellitus. F Clin Endocrinol Metab 1977;44:859-64.

18 Gale EAM, Walford S, Tattersall RB. Nocturnal hypoglycaemia and haemoglobin $A_{1}$. Lancet 1979 ;ii:1240-1.

\section{Perforation of the interventricular septum}

When a murmur develops within a few days of a myocardial infarction the most common explanation is a minor degree of mitral reflux from dysfunction of the papillary muscle. ${ }^{1}$ The murmur is not loud, there is no thrill, and the finding has little prognostic importance. A loud murmur, in contrast, means either a rupture of a papillary muscle or perforation of the interventricular septum. Rupture of a papillary muscle, usually one of the muscular heads rather than the main body, is thought to occur in $0.5-1.0 \%$ of patients who die from acute infarction. ${ }^{2}{ }^{3}$ Since the infarct may not be large and may not affect the annulus the resulting cardiogenic shock is potentially treatable by early replacement of the valve. ${ }^{2}$ The outlook is, however, grave: the operative mortality was $58 \%$ in one recent series of 42 patients. ${ }^{3}$

When the murmur is very loud, maximal at the edges of the sternum, and accompanied by a thrill the diagnosis of perforated septum is nearly certain. This is a rarer occurrence than perforation of the free ventricular wall. ${ }^{4}$ In a review of 113 patients the site of perforation was in the lower septum in $66 \%$, in the posterior portion in $17 \%$, in mid-septum in $13 \%$, and in the superior part in 3\%. few millimetres or be several centimetres across, but necropsy appearances give a false impression of the size of left to right shunt that it permits. This is usually large ${ }^{6}$ and adds a substantial load to the left ventricle, which must already have sustained an infarction affecting a quarter or more of its wall. ${ }^{7}$ The infarct is transmural with equal frequency of anterior and inferior locations. ${ }^{6-9}$ The perforation occurs in the first few days after the infarction, and the prognosis is bad, with an average survival time after perforation of only two weeks. ${ }^{5}$ Lee et al reviewed 220 published cases and found that only 24 patients had survived for more than two months. ${ }^{10}$

The poor prognosis justifies attempts at surgical repair, and the first closure of an acquired defect was reported by Cooley et al in 1957.11 By 1971, 65 patients had been treated with a $58 \%$ survival rate for more than two months, ${ }^{12}$ and the approach to the septum through the right ventricle (as for $a$ congenital defect) had given way to a left ventricular approach. The continuing poor outlook with conservative management encouraged earlier intervention, which at first had been avoided to allow time for the septal margins to fibrose. Technical improvements included an approach through the infarcted free ventricular wall with excision of necrotic tissue, placing sutures through Teflon pledgets, and the insertion of a patch to close the defect. ${ }^{8}$ At Boston between 1968 and 1977 two-thirds-24 out of 36-of patients left hospital after surgery. ${ }^{8}$ More recently, Montoya and colleagues ${ }^{6}$ have again advocated early operation: five out of seven of their patients survived whose defects were closed within two days of perforation compared with only four out of 11 whose operations were two to 14 days after. Seven patients not treated surgically died. Experience in Britain has recently been reported from Edinburgh, ${ }^{9}$ where 26 patients with ruptured septum were seen over five years. Thirteen of these were among 4850 patients with infarcts in two coronary care units, and 13 were referred from other hospitals. Operation was performed on 19 patients, with a hospital mortality of almost half. In contrast with the American series, elapse of the time between infarction and repair had a beneficial effect on the outcome of surgery: when deterioration had compelled operation within two weeks only two out of 11 patients survived, as compared with no deaths in eight patients who had held their own for more than two weeks. In the seven patients not treated by operation the longest survival was eight months. No patient benefited from repair who was in cardiogenic shock before septal rupture occurred.

When perforated ventricular septum is diagnosed cardiac catheterisation with left ventricular and coronary angiography is required to show the size of shunt, the contractile pattern of the left ventricle, the presence of mitral reflux, and the state of the coronary arteries. If operation is to be performed the surgeon may then judge whether coronary bypass grafting, excision of an aneurysm, or mitral surgery is indicated in addition to repair of the septum. The physician may choose to delay investigation if his patient is free from cardiac failure. If he was in cardiogenic shock before the perforation occurred surgery is unlikely to save him. If his condition deteriorates after perforation operation will offer him the best chance of survival.

${ }^{1}$ Heikkilä J. Mitral incompetence as a complication of acute myocardial infarction. Acta Med Scand 1967;475, suppl: 9-139.

2 Wei JY, Hutchins GM, Bulkley BH. Papillary muscle rupture in fatal acute myocardial infarction. A potentially treatable form of cardiogenic shock. Ann Intern Med 1979;90:149-53.

${ }^{3}$ Gerbode FLA, Hetzer R, Krebber HJ. Surgical management of papillary muscle rupture due to myocardial infarction. World $\mathcal{f}$ Surg 1978;2: 791-6.

* Maher JF, Mallory GK, Laurenz GA. Rupture of heart after myocardial infarction. N Englf Med 1956;255:1-10.

5 Swithinbank JM. Perforation of the interventricular septum in myocardial infarction. Br Heart $\mathcal{F} 1959 ; 21$ :562-6.

${ }^{6}$ Montoya A, McKeever L, Scanlon P, Sullivan HJ, Gunner RM, Pifarré R. Early repair of ventricular septal rupture after infarction. $A m \mathcal{F}$ Cardiol $1980 ; 45: 345-8$.

${ }^{7}$ Hutchins GM. Rupture of the interventricular septum complicating myocardial infarction: pathological analysis of 10 patients with clinically diagnosed perforations. Am Heart f 1979;97:165-73. 
${ }^{8}$ Daggett WM, Guyton RA, Mundth ED, et al. Surgery for post-myocardial infarct ventricular septal defect. Ann Surg 1977;186:260-71.

9 Forfar JC, Irving JB, Miller HC, Kitchin AH, Wheatley DJ. The management of ventricular septal rupture following myocardial infarction. $Q$ F Med 1980;49:205-17.

${ }^{10}$ Lee WY, Cardon L, Slodki SJ. Perforation of infarcted interventricular septum. Report of a case with prolonged survival, diagnosed ante mortem by cardiac catheterisation, and review of literature. Arch Intern Med $1962 ; 109: 731-41$.

11 Cooley DA, Belmonte BA, Zeis LB, Schnur S. Surgical repair of ruptured interventricular septum following acute myocardial infarction. Surgery 1957;41:930-7.

12 Kitamura S, Mendez A, Kay JH. Ventricular septal defect following myocardial infarction. Experience with surgical repair through a left ventriculotomy and review of literature. $\mathcal{F}$ Thorac Cardiovasc Surg $1971 ; 61$ :186-99.

\section{Something of ourselves}

The $B M$ F's circulation is healthy: with a weekly print order of 92000 (22000 to non-members of the BMA) we have a larger circulation than any other European weekly medical journal and the third largest in the world. Yet, like any institution the journal must move with the times and there are good reasons for making some changes now. Firstly, medical science has become more split into compartments. Few articles in the $B M F$ are read in detail by the whole range of our readers-and for the foreseeable future the trend to increasing specialisation seems likely to continue. Clinical scientists need the speed of publication and the wide circulation that only a weekly journal can provide. General practitioners want to be kept informed about the range of new ideas in their own rapidly developing specialty. If we are to provide reasonable coverage of all the major specialties then the $B M F$ will need to grow larger.

Commercial considerations point, however, in the opposite direction. Unless action is taken the $B M \mathcal{F}$ and its associated publications face a heavy financial loss. For many years these have been a profitable activity for the Association: in addition to providing every member with a free copy of the $B M \mathcal{F}$ the publishing department has almost always made a profit, which has been credited to its own reserves or to those of the BMA. Today, however, some $25 \%$ of the $B M \mathcal{F}$ and $75 \%$ of our flourishing specialist journals are exported; and in common with many other British publishers, the strong pound has crippled our profitability. With swingeing increases in the cost of paper, printing, and postage, we face a deficit unless decisive action is taken.

We believe that we should and can provide every member of the BMA with a free $B M Y$ and still balance our books. No treasurer should suddenly be asked to pay a heavy subsidy to maintain publication of the journal if there are other ways of dealing with the problem. Conversely, we are not forgetting that the $B M \mathcal{F}$ is broadly based and aimed at the whole profession: every section is important and should be available to all doctors in some form. Are all these desires compatible? We believe that they are and starting next year we hope to reconcile them.

From January we shall publish two editions of the $B M \mathcal{F}$, one subtitled "Clinical Research" and the other "Practice
Observed." Each of the editions will contain all the articles; and most features (leaders, papers and short reports, medical practice, correspondence, and the supplement) will remain as before. The two specialist sections-an expanded clinical research section and a new, eight-page feature on general practice-will be in miniprint according to the edition: thus in the "Clinical Research" edition, intended for students and hospital doctors, the eight pages of "Practice Observed" articles will be reduced to two pages of miniprint; conversely, in the "Practice Observed" edition the "Clinical Research" articles will be reduced. The advertisements in each edition will also be geared to its readership. The many pharmaceutical advertisements aimed solely at general practitioners will appear in the "Practice Observed" edition. The classified advertisements in the "Clinical Research" edition will remain unchanged. The "Practice Observed" edition will, however, include only those classified advertisements of relevance to the general practitioner. Nevertheless, great care will be taken to ensure that all advertisements of relevance to the particular readership will be included.

Clearly any such project must have built-in safeguards. Summaries of the specialist articles for hospital staff and GPs will be printed in normal-size type in the corresponding journal. Next, any reader may choose which edition he will receive-at any time, and he-may change his mind. Initially students, hospital doctors, and workers in academic medicine will be sent the "Clinical Research" edition, and trainees in general practice and family doctors the "Practice Observed" version. But in particular, we should like to hear from doctors working in community medicine, the armed Forces, or overseas about their choice of edition; for the time being we are assuming that the first will want the "Practice Observed" and the second and third groups the "Clinical Research" editions. Finally, full-size reprints of articles in miniprint will be available to BMA members free of charge on request and we will be offering a subsidised magnifying lens, similar to that supplied with the Compact Oxford Dictionary and the compact Dictionary of National Biography.

We must emphasise that, though this project has been extensively discussed with individual doctors and committees and at the Annual Representative Meeting, it remains an experiment-which will be carefully monitored. We believe the advantages to this new approach are, firstly, that we should be able to satisfy more of our readers more of the time without making the $B M \mathcal{F}$ too unwieldy; secondly, that we should become more competitive and attract increased advertising revenue; and, thirdly, that we should reduce printing, production, and postage costs (adjusting the advertisements alone could save about 25 million sheets of paper a year, quite apart from the savings on printing, production, and dispatch).

Given all the safeguards, and with careful selection of articles, we believe this experiment can succeed, without detriment to the standing of the $B M F$ or service to our readers. Indeed, it is vital that it should: by the end of 1981 the cost to the $B M Y$ of each journal supplied to a BMA member will be about $£ 40$ a year, and without some sort of change we cannot carry this burden. We hope that once they have seen the changes (and they are simpler in practice than appears from a written description) our readers will agree that these have not spoilt their familiar weekly journal and are justified by the circumstances and the results. 